\title{
Antimicrobial and healing-promoting properties of animal and plant oils for the treatment of infected wounds
}

\author{
Kennewell TL, Mashtoub S, Howarth GS, Cowin AJ \& Kopecki Z
}

Keywords Infection, antimicrobial treatments, essential oils, animal oils, chronic wounds

For referencing Kennewell TL et al. Antimicrobial and healing-promoting properties of animal and plant oils for the treatment of infected wounds. Wound Practice and Research 2019; 27(4):175-183.

DOI https://doi.org/10.33235/wpr.27.4.175-183

\section{TL Kennewell \\ BSc (Hons) \\ Regenerative Medicine, Future Industries Institute, University of South Australia, Adelaide, SA \\ S Mashtoub \\ $\mathrm{PhD}$ \\ Discipline of Physiology, Adelaide Medical \\ School, The University of Adelaide, Adelaide, SA; \\ Department of Gastroenterology, Women's and \\ Children's Hospital, SA}

\section{GS Howarth}

PhD

Discipline of Physiology, Adelaide Medical School,

The University of Adelaide, Adelaide, SA;

School of Animal and Veterinary Sciences, The

University of Adelaide, Adelaide, SA

\section{AJ Cowin}

\section{$\mathrm{PhD}$}

Regenerative Medicine, Future Industries Institute, University of South Australia, Adelaide, SA

\section{Z Kopecki*}

PhD

Regenerative Medicine, Future Industries Institute, University of South Australia, Adelaide, SA Email zlatko.kopecki@unisa.edu.au

* Corresponding author

\section{ABSTRACT}

Chronic wounds are a serious medical problem both in the hospital and community setting. The healing of chronic wounds is often compromised by colonisation of different bacterial pathogens leading to life-threatening infections. Bacterial infections are a critical contributing factor to chronic wounds and can lead to biofilm formation and inhibition of innate inflammatory responses, including the reduction of acute inflammation.

Concerningly, the overuse of systemic antibiotics and the use of traditional therapeutics, including topical antimicrobials - iodine, chlorhexidine and silver - have both greatly contributed to the development of a global increase in antimicrobial resistance. This has therefore led to a renewed interest in natural and alternative antimicrobial treatment strategies in wound care for the treatment of infected wounds.

This review summarises the pre-clinical and clinical evidence that exists for the use of natural remedies, namely essential and animal oils, as adjunctive therapeutic approaches for the treatment of infected wounds. It also discusses novel approaches in nanotechnology that are being used for the development of natural remedies aimed at improving the healing of infected chronic wounds.

\section{INTRODUCTION}

Delayed healing in chronic wounds changes the normal microbiota of the wound, leading to colonisation by more virulent microbial pathogens and subsequent infection; this is often described as a continuum spectrum from contamination to colonisation to infection ${ }^{1}$. Generally, when more than $10^{5}$ pathogenic organisms/gram of tissue colonise the wound, the wound is considered infected and localised infection develops as bacteria use different mechanisms 
to overcome the host immune responses ${ }^{2}$. Subsequently, if bacteria overcome the host immune responses and enter the surrounding tissue and blood vessels, producing a systemic host response, an infection is classified as systemic infection or sepsis ${ }^{3}$. In chronic wounds, infection is most commonly poly-microbial, although this changes over time. In early wound infection, the majority of organisms present are grampositive, with Staphylococcus aureus (being most common. Later in wound infection, Gram-negative organisms, including Escherichia coli and Pseudomonas species make up the majority of the organisms present ${ }^{3}$.

Management of wound infection is essential to reduce the presence of bacteria and promote healing ${ }^{4}$. Generally, current treatments involve cleaning the wound, treating the infection with antimicrobials ${ }^{1,2}$, and applying wound dressings ${ }^{3}$. Topical application of currently used antimicrobials - including iodine, chlorhexidine and silver - aids in reducing the presence of pathogenic bacteria in the wound. However, many of the common antimicrobials have cytotoxic effects on mammalian cells when used at the concentration required to clear the pathogenic bacteria ${ }^{1}$. In cases where infection has spread, systemic antibiotics are also used to treat infections that may clinically present as sepsis, cellulitis or abscess formation ${ }^{2}$. Unfortunately, this overuse of systemic antibiotics has given rise to the development of antimicrobial resistance and wound 'super bugs' such as methicillinresistant S. aureus (MRSA) which pose a serious threat to the community ${ }^{5}$. With drug resistance as a growing problem, choosing the appropriate treatment for wound infection is therefore becoming increasingly difficult ${ }^{6}$. Drug-resistant bacterial strains like MRSA are increasing the need for new antimicrobial products in both community and hospital settings. Consequently, natural remedies, including essential and animal oils, are gaining more interest clinically.

Essential oils are natural oils which are typically obtained by distillation and have the characteristic odour of the plant from which they are extracted ${ }^{7}$. Indeed, many natural essential - as well as animal oils - have been reported to improve healing in various pre-clinical models of animal wound healing ${ }^{4,8,9}$, and some have shown strong antimicrobial effects against the most common pathogenic bacteria present in clinical chronic wound infections ${ }^{10-12}$.

Natural remedies, including essential and animal oils such as tea tree oil and emu oil, have historically been used in wound care as safe therapeutic agents with strong antimicrobial properties. However, while these oils could be a potential adjunctive therapy for the management of difficult to treat hospital-acquired infections with multidrug-resistant strains, it is important to acknowledge that antimicrobial activity of these oils is not suitable as a stand-alone option for treating serious microbial infections of chronic wounds. This is mainly due to variations in the terpenic composition of these oils leading to variable differences in antimicrobial activity? Here we summarise evidence for the principal essential and animal oils used as natural remedies for the treatment of infected wounds. We also discuss the latest approaches in the development of adjunctive therapies using nanomedicine comprising natural remedies for the treatment of wound infection and improved tissue regeneration.

\section{METHODS}

Databases (PubMed, Medline, Scopus and Ovid) were searched for all publications between 1997 and 2019 using the search terms 'natural oils', 'plant oils' and 'animal oils' combined with 'wound healing' and 'wound infection'. This was used to select the panel of plant and animal oils with healing and antimicrobial properties as a primary focus for this review. Inclusion criteria were English language articles identifying the key search terms. We further hand-examined references of selected key papers to find additional sources of information outside our search terms. The search strategy included using broad keywords and synonyms concerning wound healing and infection, with further information relating to the animal and plant oils obtained by adding 'wound healing', 'wound infection' and 'antimicrobial' to the type of oil being searched, as well as 'clinical trials' and types of common pathogens - these are listed in Table 1. Papers relating to in-vitro, bacterial, animal and human studies were all included.

\section{THE USE OF ESSENTIAL OILS IN WOUND HEALING AND INFECTION}

Natural plant oils, or essential oils, are commonly used as an inexpensive option for skin $\mathrm{care}^{13}$. Essential oils, also referred to as volatile natural mixtures, are secondary plant metabolites extracted from the flowers, seeds, leaves and fruit of plants ${ }^{3,6}$. These natural oils are, primarily made up of unsaturated hydrocarbons termed terpenes, polyphenols and fatty acids and, together, these components are responsible for the medicinal, culinary and fragrant uses of some plants ${ }^{14}$. Many essential oils have been reported to possess antimicrobial properties in in-vitro assays ${ }^{7}$, in pre-clinical rodent models of wound repair ${ }^{14,15}$, and in human clinical trials ${ }^{11,12}$ primarily attributed to polyphenols and terpenes, (primarily monoterpenes), eugenol, cinnamaldehyde, carvacrol, and thymol'11. However, the composition of essential oils from the same plant species varies based on a variety of factors, including differences in growing conditions, in storage and processing conditions, and in the method of oil extraction ${ }^{7,16}$. This variation between oils of the same type can alter the effectiveness of the oil at treating wound infections. Additionally, it is important to acknowledge that further differences in essential oils can occur due to oil degradation by various factors including oxidation, heating and light 6,17 .

Essential oils, for example tea tree, lavender, oregano and clove oil, have also been reported to have properties that could improve healing and reduce infection in wounds ${ }^{3,9}$. These properties have been demonstrated in both in-vitro cell and bacterial assays ${ }^{18}$ as well as in pre-clinical rodent wound 


\begin{tabular}{|c|c|c|c|c|c|c|}
\hline & $\begin{array}{c}\text { Staphylococcus } \\
\text { aureus }\end{array}$ & $\begin{array}{c}\text { Pseudomonas } \\
\text { aeruginosa }\end{array}$ & $\begin{array}{c}\text { Escherichia } \\
\text { coli }\end{array}$ & $\begin{array}{l}\text { Candida } \\
\text { albicans }\end{array}$ & Effect on Healing & References \\
\hline $\begin{array}{c}\text { Tea tree } \\
\text { oil }\end{array}$ & $\begin{array}{c}\text { Inhibits at } \\
0.5 \% \mathrm{v} / \mathrm{v}\end{array}$ & $\begin{array}{l}\text { Inhibits at } \\
>5.0 \% \mathrm{v} / \mathrm{v} \\
\text { Disc diffusion } \\
\text { assay }\end{array}$ & $\begin{array}{l}\text { Inhibits at } \\
0.25 \% \mathrm{v} / \mathrm{v} \\
\text { Agar dilution } \\
\text { method }\end{array}$ & $\begin{array}{l}\text { Inhibits at } \\
0.5 \% \mathrm{v} / \mathrm{v} \\
\text { Agar dilution } \\
\text { method }\end{array}$ & $\begin{array}{l}\text { Increases macrophage numbers } \\
\text { Reduces tissue oedema } \\
\text { Accelerates wound closure }\end{array}$ & $\begin{array}{l}\text { Inhibitory concentration } \\
\text { Hammer et al., } 1999 \text { (Agar dilution method) } \\
\text { Kavanaugh and Ribbeck, } 2012 \text { (Disc diffusion assay) } \\
\text { Healing } \\
\text { Edmondson et al., } 2011 \text { (Human clinical trial) } \\
\text { Lee et al., } 2014 \text { (Human clinical trial) } \\
\text { Flores et al., } 2015 \text { (Wistar rats) }\end{array}$ \\
\hline $\begin{array}{l}\text { Lavender } \\
\text { oil }\end{array}$ & $\begin{array}{c}\begin{array}{c}\text { Inhibits at } \\
1.0 \% \mathrm{v} / \mathrm{v}\end{array} \\
\text { Agar dilution method }\end{array}$ & $\begin{array}{l}\text { Inhibits at } \\
>5.0 \% \mathrm{v} / \mathrm{v} \\
\text { Disc diffusion } \\
\quad \text { assay }\end{array}$ & $\begin{array}{l}\text { Inhibits at } \\
0.25 \% \mathrm{v} / \mathrm{v} \\
\text { Agar dilution } \\
\text { method }\end{array}$ & $\begin{array}{l}\text { Inhibits at } \\
0.25 \% \mathrm{v} / \mathrm{v} \\
\text { Agar dilution } \\
\text { method }\end{array}$ & $\begin{array}{l}\text { Enhanced TGF- } \beta \text { expression } \\
\text { Increases collagen synthesis } \\
\text { Accelerates wound closure }\end{array}$ & $\begin{array}{l}\text { Inhibitory concentration } \\
\text { Hammer et al., } 1999 \text { (Agar dilution method) } \\
\text { Kavanaugh and Ribbeck, } 2012 \text { (Disc diffusion assay) } \\
\text { Healing } \\
\text { Mori et al., } 2016 \text { (Sprague-Dawley rats) }\end{array}$ \\
\hline Clove oil & $\begin{array}{l}\text { Inhibits at } \\
0.25 \% \mathrm{v} / \mathrm{v}\end{array}$ & $\begin{array}{l}\text { Inhibits at } \\
>5.0 \% \mathrm{v} / \mathrm{v} \\
\text { Disc diffusion } \\
\text { assay }\end{array}$ & $\begin{array}{l}\text { Inhibits at } \\
0.25 \% \mathrm{v} / \mathrm{v} \\
\text { Agar dilution } \\
\text { method }\end{array}$ & $\begin{array}{l}\text { Inhibits at } \\
0.12 \% \mathrm{v} / \mathrm{v} \\
\text { Agar dilution } \\
\text { method }\end{array}$ & $\begin{array}{l}\text { Decreased inflammation and reduced } \\
\text { odour of infected wounds } \\
\text { Increased fibroblast migration } \\
\text { Accelerates wound closure } \\
\text { Promotes angiogenesis } \\
\text { Prevents scaring }\end{array}$ & $\begin{array}{l}\text { Inhibitory concentration } \\
\text { Hammer et al., } 1999 \text { (Agar dilution method) } \\
\text { Kavanaugh and Ribbeck, } 2012 \text { (Disc diffusion assay) } \\
\text { Healing } \\
\text { Akhmetova et al., } 2016 \text { (Human clinical trial) } \\
\text { Alam et al., } 2017 \text { (Wistar rats) } \\
\text { Singh et al., } 2018 \text { (Balb/c mice) } \\
\text { Li et al., } 2019 \text { (Balb/c mice) }\end{array}$ \\
\hline Emu oil & $\begin{array}{c}\text { No effect } \\
\text { Disc diffusion assay }\end{array}$ & No data & $\begin{array}{c}\text { No effect } \\
\text { Disc diffusion } \\
\text { assay }\end{array}$ & $\begin{array}{c}\text { No effect } \\
\text { Disc diffusion } \\
\text { assay }\end{array}$ & $\begin{array}{l}\text { Improves keratinization, } \\
\text { fibrillogenesis and wound } \\
\text { regeneration } \\
\text { Protects against oxidative damage } \\
\text { Increases mature hair follicles around } \\
\text { wound }\end{array}$ & $\begin{array}{l}\text { Inhibitory concentration } \\
\text { Riley and Carson } 1999 \text { (Disc diffusion assay) } \\
\text { Healing } \\
\text { Politis and Dmytrowich, } 1998 \text { (Wistar rats) } \\
\text { Rodrigues et al. } 2012 \text { (Wistar rats) } \\
\text { Afshar et al., } 2016 \text { (Balb/c mice) }\end{array}$ \\
\hline $\begin{array}{l}\text { Ostrich } \\
\text { oil }\end{array}$ & $\begin{array}{c}\text { Reduces bacterial } \\
\text { count at } 2.00 \% \mathrm{w} / \mathrm{w} \\
\text { Balb/c mice }\end{array}$ & $\begin{array}{c}\text { Reduces } \\
\text { bacterial count } \\
\text { at } 2.00 \% \mathrm{w} / \mathrm{w} \\
\text { Balb/c mice }\end{array}$ & No data & No data & $\begin{array}{l}\text { Reduces inflammation } \\
\text { Increases fibroblast proliferation and } \\
\text { collagen synthesis } \\
\text { Promotes angiogenesis } \\
\text { Accelerates dermal wound } \\
\text { maturation }\end{array}$ & $\begin{array}{l}\text { Inhibitory concentration } \\
\text { Farahpour et al., } 2018 \text { (Balb/c mice) } \\
\text { Healing } \\
\text { Farahpour et al., } 2018 \text { (Balb/c mice) }\end{array}$ \\
\hline $\begin{array}{c}\text { Crocodile } \\
\text { oil }\end{array}$ & $\begin{array}{l}\text { Bacterial growth } \\
\text { reduced by half at } \\
10 \% \mathrm{v} / \mathrm{v} \\
\text { Bacterial culture } \\
\text { broth }\end{array}$ & No data & No data & $\begin{array}{l}\text { Bacterial } \\
\text { growth } \\
\text { reduced by } \\
\text { half at } 5 \% \mathrm{v} / \mathrm{v} \\
\text { Bacterial } \\
\text { culture broth }\end{array}$ & $\begin{array}{l}\text { Improves epidermal organisation } \\
\text { Improves hair follicle formation } \\
\text { Improves collagen deposition } \\
\text { Accelerates wound closure }\end{array}$ & $\begin{array}{l}\text { Inhibitory concentration } \\
\text { Buthelezi et al., } 2012 \text { (Bacterial culture broth) } \\
\text { Healing } \\
\text { Li et al., } 2012 \text { (Wistar rats) } \\
\text { Li et al., } 2017 \text { (Wistar rats) }\end{array}$ \\
\hline
\end{tabular}

and infection models ${ }^{14,15,19}$ and human clinical studies ${ }^{11,12}$. Other oils, such as emu oil, have yet to demonstrate antimicrobial properties; however, in the experimental setting, topically applied emu oil has been demonstrated to decrease inflammation, improve epidermal keratinisation, and increase the number of mature hair follicles around the wound in preclinical animal models of wound repair ${ }^{8}$. Indeed, bacterial and mammalian cell in-vitro assays and pre-clinical animals models have demonstrated that a mixture of essential oils with potent antibacterial and healing-promoting properties could provide the optimal approach to treat infected wounds using natural remedies ${ }^{20}$. Additionally, different pre-clinical animal studies have shown that both oral and topical administration of natural oils have benefits in promoting wound healing by accelerating recovery from the inflammatory phase of wound repair, while some essential oils have synergistic effects against pathogenic wound bacteria in combination with recommended antibiotics ${ }^{15,21,22}$. Table 1 summarises the minimum inhibitory concentrations (MICs) of selected essential and animal oils discussed in this review against the four major pathogenic bacteria normally present in chronic wounds and their subsequent effects on wound healing.
Oil from Melaleuca alternifolia (tea tree) has been used by Indigenous Australian people for skin infections and wound healing for thousands of years ${ }^{18}$. Today, tea tree oil and its components have been integrated into various skin care products ${ }^{3}$. Tea tree oil is comprised of a complex mixture of terpenes and hydrocarbons, with the most active components being terpinen-4-ol and 1,8-cineole, giving tea tree oil its antimicrobial, antifungal and anti-inflammatory properties $^{3,17}$. The antimicrobial properties of tea tree oil have been shown to inhibit $E$. coli and $S$. aureus in in-vitro bacterial assays with minimum inhibitory concentrations of $0.25 \%$ and $0.5 \%$ respectively ${ }^{7}$. Additionally, tea tree oil inhibits Pseudomonas aeruginosa biofilms in in-vitro bacterial assays with minimum inhibitory concentration of $5 \%{ }^{23}$.

In the context of clinical wound healing, its biological effects are mediated via an enhanced innate immunity response, attributed to its ability to activate monocyte differentiation into pathogen-killing macrophages and reduce tissue oedema ${ }^{11,12,24}$. Importantly, it has been shown that using water-miscible tea tree oil (3.3\%) solution as an aspect of the wound dressing cleansing regimen at each dressing change is effective against MRSA and can improve the healing of 
human infected wounds ${ }^{12,25,26}$. In addition, tea tree oil is as effective as the standard antibiotic treatment mupirocin in clearing MRSA infection; it has been demonstrated to clear MRSA infection in $41 \%$ of patients where no mupirocin resistance was present, while mupirocin - the "gold standard antibiotic treatment" - cleared MRSA infection in 49\% of patients ${ }^{25}$. This tea tree oil preparation hence allowed previously non-healing infected human wounds to heal ${ }^{12}$ and significantly reduced MRSA colonisation while promoting healing when added to wounds after saline wash and before dressing application ${ }^{26}$. Additionally, previously reported problems of wound maceration and colonisation by Gramnegative bacteria did not occur in this study ${ }^{12}$.

Another essential oil, lavender oil, is used predominantly in aromatherapy and can be found in a number of cosmetic and therapeutic settings. Historically, lavender oil was used by ancient Romans and Greeks for its antibacterial and antifungal properties post-burn injuries and insect bites ${ }^{27}$. The properties of lavender oil are highly dependent on plant source ${ }^{3}$, resulting in different compositions; however, the main constituents of lavender oil include linalool and linaly $\left.\right|^{3,15,27}$, both of which have marked anti-inflammatory and antimicrobial properties ${ }^{15}$. Lavender oil comprises four main lavender types - Lavandula latifolia, Lavandula angustifolia, Lavandula stoechas and Lavandula intermedia. Lavender oil from different lavender types has been used for different clinical applications, including as an abortifacient, a diuretic and for the treatment of headaches and insomnia ${ }^{27}$. Two variations of $L$. angustifolia (French lavender and Tasmanian lavender) have been shown to inhibit $S$. aureus activity at $1 \%$ in in-vitro bacterial studies, with studies also showing $L$. angustifolia to have a minimum inhibitory concentration of $0.25 \%$ against $E$. coli and Candida albicans and an inhibitory concentration $>5 \%$ for $P$. aeruginosa ${ }^{7,23}$. Additionally, topical application of only $1 \%$ of $L$. angustifolia oil has been demonstrated to improve cutaneous healing in Sprague Dawley rats with $10 \mathrm{~mm}$ diameter excisional wounds, significantly increasing TGF- $\beta$ expression, fibroblast proliferation, collagen synthesis and accelerated granulation tissue formation ${ }^{15}$. Lavender oil treatment also increased the myofibroblast population, resulting in increased wound contraction and reduced wound area compared to untreated wounds of Sprague Dawley rats demonstrating healingpromoting properties ${ }^{15}$.

Syzygium aromaticum (clove) or clove oil also has antioxidative, antibacterial, anti-inflammatory and analgesic properties $^{14,21,28,29}$ that have been used in herbal medicine to treat cuts and burns, to provide pain relief from toothache, and to treat tooth infections ${ }^{29}$. Clove oil can be highly cytotoxic to human skin cells in-vitro, with $54-73 \%$ of the cytotoxicity being attributed to eugenol ${ }^{29}$. Eugenol is the main component in clove oil, making up $71-90 \%$ of the oil and is primarily responsible for its antimicrobial properties ${ }^{21,28}$. Eugenol is generally regarded as safe and is often added to food for its spicy flavour ${ }^{28,29}$; however, at a concentration of
$0.06 \%$, eugenol can become highly cytotoxic to human skin cells $^{29}$. Despite this cytotoxicity, eugenol at a concentration of $0.001 \%$ has been shown to have a protective effect on skin photoaging ${ }^{28}$. Clove oil has also been shown to improve wound healing in pre-clinical animal models of wound healing ${ }^{14,21}$, and exhibits antibacterial activity in in-vitro bacterial assays against $E$. coli and S. aureus, with minimum inhibitory concentrations of $0.25 \%$ for both, while its effects on C. albicans are observed at $0.12 \%$ and against $P$. aeruginosa at $>5 \% \%^{7,23}$. Interestingly, application of clove oil significantly enhanced the therapeutic effectiveness of Fluconazole drug and eradication of dual-species biofilms ( $C$. albicans/ $S$. aureus) in in-vitro bacterial assays compared to antibiotics alone ${ }^{30}$. Indeed, in-vitro bacterial studies focused on understanding how clove oil exerts its antibacterial activity showed that clove oil could increase the cell wall permeability of gram-positive $S$. aureus and lead to inhibition of bacterial DNA and protein synthesis ${ }^{31}$.

In pre-clinical wound healing studies, the effect of clove oil (eugenol) has also been attributed to accelerated healing of diabetic wounds via its effects on reduced lectinlike oxidised low-density lipoprotein receptor 1/ NF- $\mathrm{BB}$ induced dysfunction in endothelial cells and promotion of angiogenesis ${ }^{32}$. Additionally, incorporation of clove oil into a wound dressing has been shown to improve wound healing via increased fibroblast migration and deposition of collagen that resulted in significantly decreased scar formation in preclinical models of wound repair in mice ${ }^{14}$. Clinically, topical applications of clove oil have been suggested as an effective strategy for controlling odour of chronic wounds and for decreasing inflammatory responses post-infection ${ }^{33}$.

\section{THE USE OF ANIMAL OILS IN WOUND HEALING AND INFECTION}

Animal oils have been used in various traditional medicines, for example, crocodile oil has been used as an ointment for burns and scalds in traditional Chinese and Southeast Asian medicine ${ }^{34,35}$, and emu oil has been used by Indigenous Australian people to aid wound regeneration ${ }^{18,36}$. Similar to essential oils, the composition of animal oils can vary with different environmental conditions, such that the same species of animal from different areas can have variations in compositions ${ }^{8}$. However, unlike essential oils, animal oils such as emu oil require less refining and are more readily metabolised $^{36}$. While the majority of research has focused on the use of essential oils in wound healing applications, the antibacterial and healing properties of animal oils are now also gaining attention as potential sources of novel antimicrobials.

Oil from the flightless bird Dromaius novaehollandiae (emu) was used by Indigenous Australian people to treat burns, scrapes, and to accelerate wound healing ${ }^{18,36}$ and is still used today as a complementary medicine to enhance healing ${ }^{8}$. Emu oil is collected from the subcutaneous and retroperitoneal fat of the emu, consisting primarily of fatty 
acids, including omega-9 (oleic acid; $42 \%$ ), omega-6 (linoleic acid; $21 \%)$, palmitic acid $(21 \%)$, and omega-3 ( $\alpha$-linolenic acid; $1 \%)^{37}$. The anti-inflammatory properties of emu oil have been shown to reduce clinical indicators of disease, decrease tissue inflammation, and promote intestinal repair in various clinical inflammatory conditions, including gastrointestinal disorders ${ }^{37-40}$ and polyarthritis ${ }^{36}$.

In wound healing, emu oil has been shown to have a marked positive effect on skin regeneration by significantly increasing the number of mature hair follicles in the wound margins and improving dermal fibrillogenesis and collagen production compared to untreated controls in a pre-clinical murine model of wound repair8. The positive effects of emu oil have been attributed to its high oleic acid and linoleic acid composition which has been shown to increase TNF- $\alpha$ concentration and $\mathrm{NF}-\mathrm{KB}$ activation at 1 hour post-wounding, and reduce IL-1 and IL-6 proinflammatory cytokine levels as well as NF- $\mathrm{KB}$ activation at 24 hours post-wounding in murine models of healing ${ }^{8}$. Additionally, emu oil effects on infected murine wounds have demonstrated protection against oxidative damage, a critical desired property for potential antimicrobial treatment ${ }^{22}$. These findings are in agreement with studies which showed that topical applications of linoleic acid on wounds of mice and rats improved the rate of wound healing, increased angiogenesis and reduced inflammation, while clinical treatment of human pressure ulcers with linoleic acid increased hydration and elasticity ${ }^{41,42}$.

However, despite its positive effects on wound healing, emu oil has also been shown to delay healing in one preclinical wound healing study using mice with $1 \mathrm{~cm}$ diameter burn wounds, by prolonging the inflammatory stage when applied immediately after wound formation ${ }^{8}$. Nevertheless, emu oil application still improved overall healing of the wound site. In that study, inflammatory cell density, primarily polymorphonuclear leukocytes, was increased in the emu oil groups on all days when compared with the control groups ${ }^{8}$. A separate pre-clinical study in Wistar rats with $6 \mathrm{~mm}$ diameter excisional wounds showed that emu oil treatment improved wound re-epithelialisation when applied 24 hours post-wound formation, with no effect on wound contraction compared to control ${ }^{43}$. In that same study, an emu oil lotion comprised of emu fat and ultra-purified oil, vitamin $E$ and botanical oil carrier resulted in almost a two-fold increase in wound contraction compared to untreated controls; an improvement also previously observed when application was delayed 48 hours compared to controls ${ }^{43}$.

Struthio camelus (ostrich) has been farmed since the mid1880s for feathers and hides, and more recently for meat and oil18. Ostrich oil mainly consists of oleic acid (30.39\%), linoleic acid (17.32\%), palmitic acid (32.11\%), and palmitoleic acid $(9.12 \%)^{44}$. This oil has been used in cosmetics and may have wound healing and anti-inflammatory activity ${ }^{18}$. The potential wound healing ability of ostrich oil has been tested in Balb/c mice with excisional wounds infected with $S$. aureus and $P$. aeruginosa ${ }^{44}$. Ostrich oil was mixed with an ointment base made from soft paraffin $(90 \%)$, hard paraffin (5\%) and lanolin (5\%) such that the ointment contained either $2 \%$ or $4 \%$ ostrich oil. Compared to the ointment base, both $2 \%$ and $4 \%$ ostrich oil ointments decreased bacterial count and enhanced wound healing by reducing inflammation, increasing fibroblast proliferation and enhancing collagen deposition ${ }^{44}$. Additionally, compared to ointment base and mupirocin antibiotic treatment, ostrich oil ointment increased the number of blood vessels present in the wound by day 8 post-wound formation ${ }^{44}$. Ostrich oil treatment of $S$. aureus and $P$. aeruginosa infected wounds showed significantly decreased TGF- $\beta$ and upregulated FGF-2, and VEGF expression leading to enhanced angiogenesis and fibroblast distribution which enhanced collagen biosynthesis and dermal maturation ${ }^{44}$.

Another animal oil, crocodile oil, is rich in monounsaturated and polyunsaturated fats and has been used in ointments for burns and scalds in traditional Chinese and south east Asian medicine ${ }^{34}$, and in Africa for skin rashes and to improve wound healing ${ }^{35}$. The oil from Crocodylus siamensis (Siamese crocodile) is mainly composed of oleic acid (30.47\%), linoleic acid (11.74\%), and palmitoleic acid (5.67\%) and has been shown to accelerate healing in pre-clinical models of burn wound injury in Wistar rats compared to silver sulfadiazine treatment ${ }^{34}$. Additionally, studies have shown that Siamese crocodile oil can promote skin regeneration, collagen deposition and reduce scarring in second degree pre-clinical burn wound models in Wistar rats both as pure oil and when combined with a herbal ointment containing: Arnebia euchroma, root, dried; Astragalus membranaceu, root, dried; Savia miltiorrhiza, root, dried; Sanguisorba officinalis, root, dried; and Borneolum syntheticum ${ }^{34,35}$. This suggests the potential benefits of using a combination of essential and animal oils in the treatment of infected wounds, while the effect on skin scarring - which appears to be unique to crocodile oils - warrants further investigation in pre-clinical wound healing studies using large animals. Figure 1 provides a schematic diagram summarising the antimicrobial and antiinflammatory effects of essential and animal oils as oral or topical treatments for infected wounds.

\section{NANOMEDICINE APPROACHES FOR DEVELOPMENT OF ADJUNCTIVE THERAPIES CONTAINING NATURAL ESSENTIAL AND ANIMAL OILS}

In order to develop effective adjunctive therapies containing natural essential and animal oils for the treatment of infected wounds clinically, the current main research focus is on improving the solubility and stability of these oils as well as developing different modes of delivery. Studies have shown that using different nanosystems that encapsulate these oils not only improves their solubility and stability, but also protects them from environmental factors that may cause chemical degradation while increasing their bioavailability and bioefficacy, especially antimicrobial and anti-inflammatory properties ${ }^{8,17,21}$. For example, a nano- 
emulsion comprised of clove oil (1\%), Triacetin (8\%), Tween80 (15\%), labrasol (15\%) and water (61\%), administered orally each day for 21 days to albino Wistar rats was shown to improve wound closure of a $500 \mathrm{~mm}^{2}$ excisional wound compared to pure clove oil, the nano-emulsion without clove oil, and an untreated control ${ }^{21}$. Nanoparticles have the ability to protect and carry drugs or oils to specific targets in the body, enabling slower degradation, enhancing cutaneous penetration and improved treatment efficacy with lower systemic absorption ${ }^{45}$. Additionally, use of nanoparticles reduces the unwanted side-effects, while their incorporation into biodegradable scaffolds has demonstrated safer, longer and slower release of drugs/antibodies/silver ions to infected wounds, resulting in improved wound healing and decreased scarring ${ }^{45}$. The nanosystems used most commonly are either polymer-based (nanocapsules, nanoparticles, nanofibers, nanogels) or lipid-based (liposomes, solid lipid nanoparticles, nanostructured lipid carriers) and there is a wide range of literature on these approaches ${ }^{45}$.

A recent systematic review of various rodent studies has revealed a significant amount of evidence on the use of essential oils as wound healing agents, and that their incorporation with chitosan, alginate, gelatin or collagen biopolymers results in active films or nanofibre dressings which have marked antioxidant, anti-inflammatory and antimicrobial activity ${ }^{46,47}$. For example, one study has shown that tea tree oil loaded into a chitosan hydrogel together with silver ions exhibited marked antimicrobial activity in in-vitro bacterial assays against $P$. aeruginosa, $S$. aureus and $C$. albicans, and further improved the antimicrobial activity by lowering the effective concentration of silver ions required, thereby reducing potential toxic effects on the healthy tissue surrounding the wound ${ }^{48}$. A similar in-vitro study using clove oil and chitosan hydrogel in bacterial assays has also reported promising anti-microbial and healing effects which were enhanced by delivering essential oil using nanotechnology approaches ${ }^{17}$.

Additionally, studies using hydrogels containing nanocapsules and nanoemulsions of tea tree oil have demonstrated both antiedematogenic and promoted healing in rodent model of wound repair in-vivo ${ }^{49}$. In another study, dressings with either $5 \%$ clove oil or $10 \%$ sandalwood oil were applied

Figure 1. The antimicrobial and anti-inflammatory effects of essential and animal oils as oral or topical treatments for infected wounds.

A

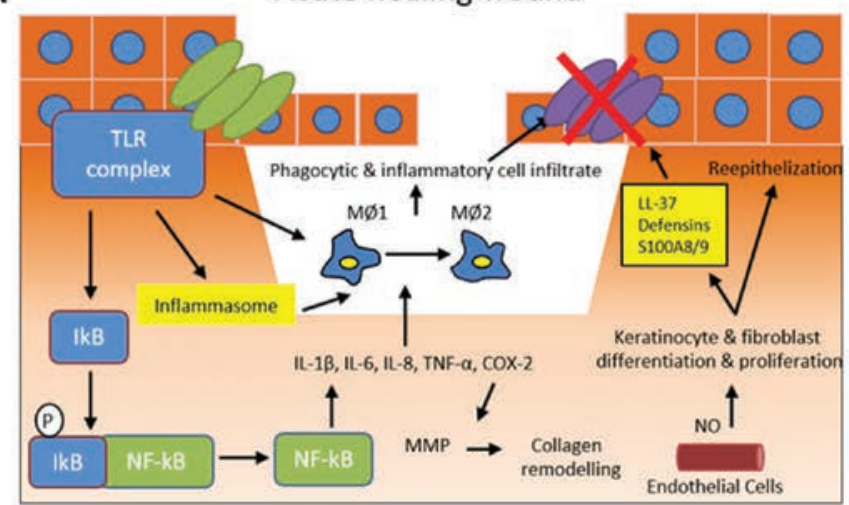

B

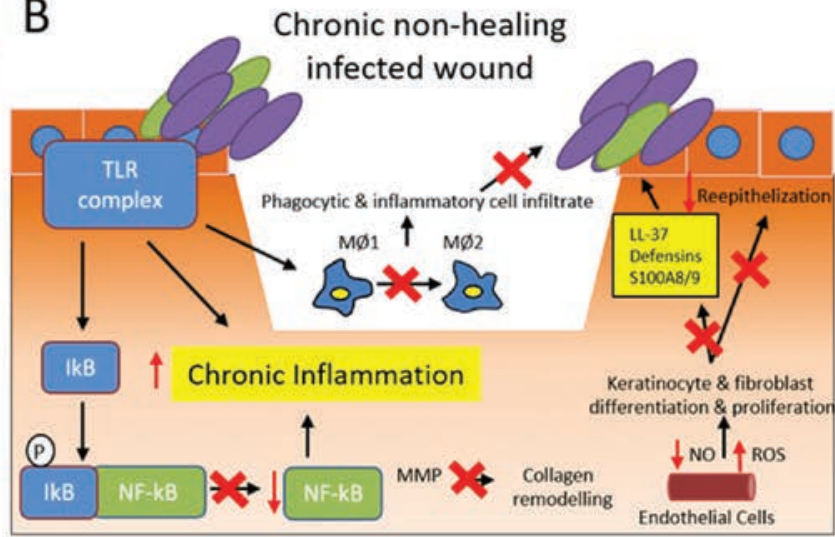

Pathogenic bacteria

\section{Commensal bacteria}

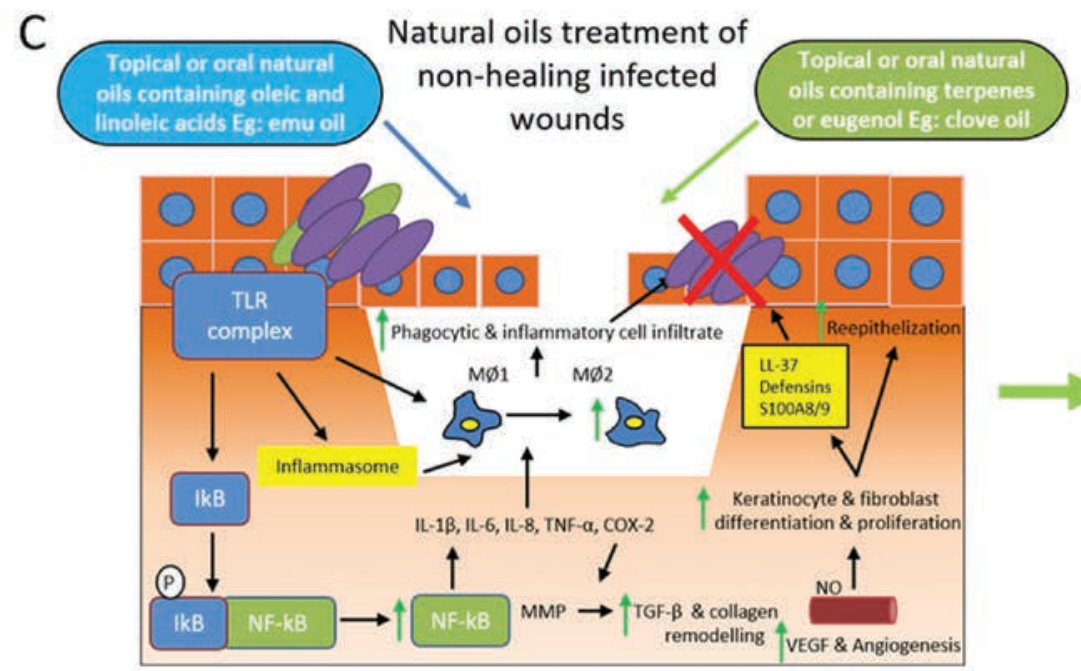

Decreased Inflammation Increased Bactericidal Activity Increased Angiogenesis Increased Dermal Maturation Accelerated Wound Closure Reduced Scar Formation 
to $10 \times 10 \mathrm{~mm}^{2}$ wounds on Balb/c mice for 21 days. By day 21 , all mice treated with either oil had full wound closure, unlike mice given dressings without oil, again demonstrating the feasibility of using nanotechnology delivery systems to incorporate natural oils in hydrogels and/or dressings resulting in beneficial wound healing outcomes ${ }^{14}$.

A recent pre-clinical in-vivo study has demonstrated that solubility and stability of eugenol (the main component of clove oil) can be significantly enhanced by the creation of a bioactive carboxy-methylcellulose (CMC) hydrogel loaded with inclusion complexes of eugenol with $\beta$-cyclodextrin $(\beta-C D)$ for accelerating healing in full thickness wounds in a diabetic mouse model ${ }^{32}$. Encapsulating the hydrophobic eugenol with $\beta-C D$ into its cavity to form inclusion complexes overcame the issues of solubility and stability, allowing slow and sustained release of eugenol (EG) from EG- $\beta$ $\mathrm{CD} / \mathrm{CMC}$ hydrogel into the infected diabetic wounds ${ }^{32}$. Subsequently, this allowed eugenol to reduce the chronic wound inflammation and promote healing by inhibiting the secretion of inflammatory factors (TNF- $\alpha$ and IL-6) and promoting angiogenesis by decreasing MMP-9 and increasing VEGF respectively ${ }^{32}$. This allowed eugenol to exert its antibacterial effect on $S$. aureus and $E$. coli while decreasing inflammation, promoting neovascularisation of the wounds, and consequently improving the rate of wound healing (Figure 2) ${ }^{32}$. Taken together, these studies clearly demonstrate the feasibility and rationale for using essential and animal oils as potential adjuvant therapies to counteract pathogens with multiple antibiotic resistance or to be used as enhancers of conventional therapy approaches. However, further clinical studies are required to demonstrate the optimal nanotechnology approaches by which we can safely deliver these compounds to wounds.

\section{CONCLUSION}

Natural remedies including essential oils and animal oils have a real potential to aid in the clinical management of chronic infected wounds. Used in place of, or alongside, traditional treatments, the antimicrobial properties of essential and animal oils have the potential for use where drug resistance makes selecting the ideal treatment near impossible. The high volatility and lipophilicity of essential and animal oils allows them to penetrate the cell membrane and exert biological

Figure 2. The antibacterial effect of eugenol on S. aureus and E. coli.

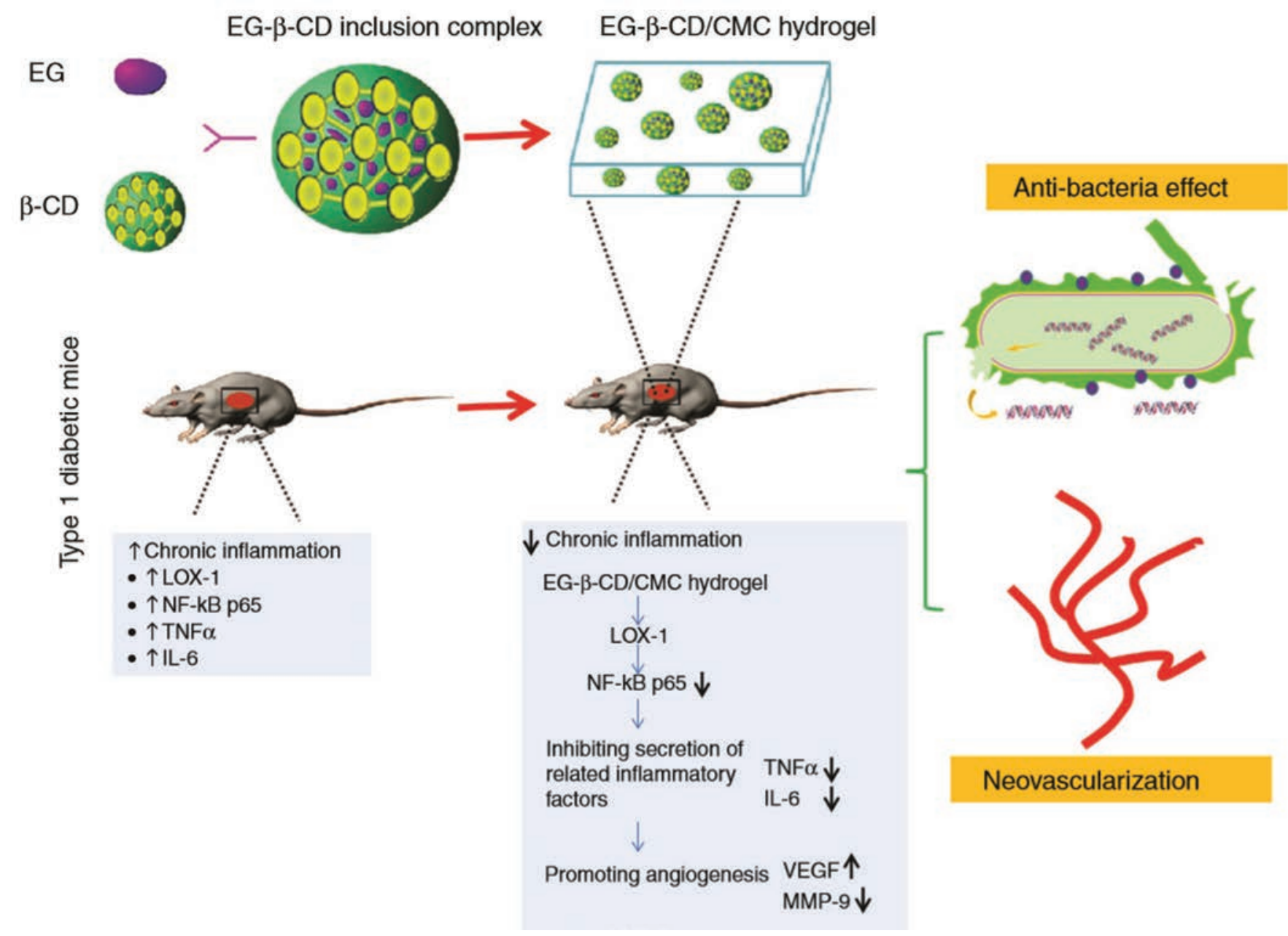


effects. Additionally, due to their physiochemical properties, oils prevent water loss and the invasion of microorganisms, hence assisting in reducing the rates of colonisation and subsequent wound infection ${ }^{50}$.

Natural products obtained from medicinal plants have become an important alternative source of new substances for combating wound infections as, in addition to lowering costs, these compounds also have reduced toxicity against mammalian cells ${ }^{22}$. Indeed, the topical administration of essential and animal oils on open wounds is a low-cost alternative in the treatment of wounds; however, literature on this approach is relatively scarce.

It should also be noted that application of these oils on wounds has a different effect at different stages of wound healing. In the first phase, treatment with oils results in immunomodulatory effects which dampen the inflammation and oxidative stress while promoting antimicrobial activity. In the second phase, treatment with oils promotes re-epithelialisation, angiogenesis and development of granulation tissue while their application in the third phase of wound healing appears to alter fibroblast and keratinocyte growth, improve collagen deposition, and decrease early scar formation ${ }^{20}$. Consequently, these compounds present great potential for the development of new low-cost therapeutic approaches for wound repair. However, larger randomised clinical trials are required to further examine the efficacy of oils as natural remedies and adjuvant wound therapy as well as determining the optimal dose and safety of these compounds for wound treatment and, ultimately, the mechanisms by which they exert their beneficial effects.

\section{CONFLICT OF INTERESTS}

Authors declare no conflict of interest.

\section{FUNDING}

This work was supported by the Australian Postgraduate Award scholarship to TL Kennewell. Z Kopecki is supported by the Future Industries Institute, Foundation Fellowship from the University of South Australia. AJ Cowin is supported by the NHMRC Senior Research Fellowship (GNT\#1102617).

\section{REFERENCES}

1. Edwards R, Harding KG. Bacteria and wound healing. Curr Opin Infect Dis 2004;17(2):91-6.

2. Siddiqui AR, Bernstein JM. Chronic wound infection: facts and controversies. Clin Dermatol 2010;28(5):519-26.

3. Negut I, Grumezescu V, Grumezescu AM. Treatment strategies for infected wounds. Molecules 2018;23(9).

4. Mazutti da Silva SM, Rezende Costa CR, Martins Gelfuso G, Silva Guerra EN, de Medeiros Nobrega YK, Gomes SM, et al. Wound healing effect of essential oil extracted from Eugenia dysenterica DC (Myrtaceae) leaves. Molecules 2018;24(1).

5. O'Neill J. Review of antimicrobial resistance: tackling a crisis for the health and welfare of nations. London: Review on Antimicrobial Resistance; 2014.
6. Saporito F, Sandri G, Bonferoni MC, Rossi S, Boselli C, Icaro Cornaglia A, et al. Essential oil-loaded lipid nanoparticles for wound healing. Int J Nanomedicine 2018;13:175-86.

7. Hammer KA, Carson CF, Riley TV. Antimicrobial activity of essential oils and other plant extracts. J Appl Microbiol 1999;86(6):985-90.

8. Afshar M, Ghaderi R, Zardast M, Delshad P. Effects of topical emu oil on burn wounds in the skin of Balb/c mice. Dermatol Res Pract 2016;2016:6.

9. Pazyar N, Yaghoobi R, Rafiee E, Mehrabian A, Feily A. Skin wound healing and phytomedicine: a review. Skin Pharmacol Physiol 2014;27(6):303-10.

10. Dorman HJ, Deans SG. Antimicrobial agents from plants: antibacterial activity of plant volatile oils. J Appl Microbiol 2000;88(2):308-16.

11. Lee RLP, Leung PHM, Wong TKS. A randomized controlled trial of topical tea tree preparation for MRSA colonized wounds. Int J Nurs Sci 2014;1(1):7-14.

12. Edmondson M, Newall N, Carville K, Smith J, Riley TV, Carson CF. Uncontrolled, open-label, pilot study of tea tree (Melaleuca alternifolia) oil solution in the decolonisation of methicillin-resistant Staphylococcus aureus positive wounds and its influence on wound healing. Int Wound J 2011;8(4):375-84.

13. Vaughn AR, Clark AK, Sivamani RK, Shi VY. Natural oils for skinbarrier repair: ancient compounds now backed by modern science. Am J Clin Dermatol 2018;19(1):103-17.

14. Singh S, Gupta A, Sharma D, Gupta B. Dextran based herbal nanobiocomposite membranes for scar free wound healing. Int $J$ Biol Macromol 2018;113:227-39.

15. Mori HM, Kawanami H, Kawahata H, Aoki M. Wound healing potential of lavender oil by acceleration of granulation and wound contraction through induction of TGF-beta in a rat model. BMC Complement Altern Med 2016;16:144.

16. Sakkas H, Papadopoulou C. Antimicrobial activity of basil, oregano, and thyme essential oils. J Microbiol Biotechnol 2017;27(3):429-38.

17. Pereira Dos Santos E, Nicacio PHM, Coelho Barbosa F, Nunes da Silva H, Andrade ALS, Lia Fook MV, et al. Chitosan/essential oils formulations for potential use as wound dressing: physical and antimicrobial properties. Materials (Basel) 2019;12(14).

18. Bennett DC, Leung G, Wang E, Ma S, Lo BK, McElwee KJ, et al. Ratite oils promote keratinocyte cell growth and inhibit leukocyte activation. Poult Sci 2015;94(9):2288-96.

19. Mahboubi M, Feizabadi MM, Khamechian T, Kazempour N, Razavi Zadeh M, Sasani F, et al. The effect of Oliveria decumbens and Pelargonium graveolens on healing of infected skin wounds in mice. World J Plast Surg 2016;5(3):259-64.

20. Costa MF, Durco AO, Rabelo TK, Barreto RSS, Guimaraes AG. Effects of carvacrol, thymol and essential oils containing such monoterpenes on wound healing: a systematic review. J Pharm Pharmacol 2019;71(2):141-55.

21. Alam P, Ansari MJ, Anwer MK, Raish M, Kamal YK, Shakeel F. Wound healing effects of nanoemulsion containing clove essential oil. Artif Cells Nanomed Biotechnol 2017;45(3):591-7.

22. Rodrigues HG, Vinolo MA, Magdalon J, Vitzel K, Nachbar RT, Pessoa AF, et al. Oral administration of oleic or linoleic acid accelerates the inflammatory phase of wound healing. J Invest Dermatol 2012;132(1):208-15.

23. Kavanaugh NL, Ribbeck K. Selected antimicrobial essential oils eradicate Pseudomonas spp. and Staphylococcus aureus biofilms. Applied and environmental microbiology 2012;78(11):4057-61.

24. Halcon L, Milkus K. Staphylococcus aureus and wounds: a review of tea tree oil as a promising antimicrobial. Am J Infect Control 2004;32(7):402-8. 
25. Dryden MS, Dailly S, Crouch M. A randomized, controlled trial of tea tree topical preparations versus a standard topical regimen for the clearance of MRSA colonization. J Hosp Infect 2004;56(4):283-6.

26. Lee RLP, Leung PHM, Wong TKS. A randomized controlled trial of topical tea tree preparation for MRSA colonized wounds. Int J Nurs Sci 2014;1(1):7-14.

27. Cavanagh HM, Wilkinson JM. Biological activities of lavender essential oil. Phytotherapy Res: PTR 2002;16(4):301-8.

28. Hwang E, Lin P, Ngo HTT, Yi TH. Clove attenuates UVB-induced photo damage and repairs skin barrier function in hairless mice. Food Funct 2018;9(9):4936-47.

29. Prashar A, Locke IC, Evans CS. Cytotoxicity of clove (Syzygium aromaticum) oil and its major components to human skin cells. Cell Prolif 2006;39(4):241-8.

30. Budzynska A, Rozalska S, Sadowska B, Rozalska B. Candida albicans/Staphylococcus aureus dual-species biofilm as a target for the combination of essential oils and fluconazole or mupirocin. Mycopathologia 2017;182(11-12):989-95.

31. Xu JG, Liu T, Hu QP, Cao XM. Chemical composition, antibacterial properties and mechanism of action of essential oil from clove buds against Staphylococcus aureus. Molecules 2016;21(9).

32. LiM, LiF, Wang T,ZhaoL, ShiY. Fabrication of carboxymethylcellulose hydrogel containing beta-cyclodextrin-eugenol inclusion complexes for promoting diabetic wound healing. J Biomater Appl 2019:885328219873254.

33. Akhmetova A, Saliev T, Allan IU, Illsley MJ, Nurgozhin T, Mikhalovsky S. A comprehensive review of topical odor-controlling treatment options for chronic wounds. J Wound Ostomy Continence Nurs 2016;43(6):598-609.

34. Li HL, Chen LP, Hu YH, Qin Y, Liang G, Xiong YX, et al. Crocodile oil enhances cutaneous burn wound healing and reduces scar formation in rats. Acad Emerg Med 2012;19(3):265-73.

35. Li HL, Deng YT, Zhang ZR, Fu QR, Zheng YH, Cao XM, et al. Evaluation of effectiveness in a novel wound healing ointment: crocodile oil burn ointment. Afr J Tradit Complement Altern Med 2017;14(1):62-72.

36. Whitehouse MW, Turner AG, Davis CK, Roberts MS. Emu oil(s): a source of non-toxic transdermal anti-inflammatory agents in Aboriginal medicine. Inflammopharmacol 1998;6(1):1-8.

37. Chartier LC, Howarth GS, Lawrance IC, Trinder D, Barker SJ, Mashtoub S. Emu oil improves clinical indicators of disease in a mouse model of colitis-associated colorectal cancer. Dig Dis Sci 2018;63(1):135-45.

38. Mashtoub S, Cheah KY, Lymn KA, Howarth GS. Intestinal homeostasis is restored in mice following a period of intestinal growth induced by orally administered emu oil. Exp Biol Med (Maywood) 2018;243(11):945-52.
39. Mashtoub S, Lampton LS, Eden GL, Cheah KY, Lymn KA, Bajic $\mathrm{JE}$, et al. Emu oil combined with lyprinol reduces small intestinal damage in a rat model of chemotherapy-induced mucositis. Nutr Cancer 2016;68(7):1171-80.

40. Safaeian R, Howarth GS, Lawrance IC, Trinder D, Mashtoub S. Emu oil reduces disease severity in a mouse model of chronic ulcerative colitis. Scand J Gastroenterol 2019;54(3):273-80.

41. Rodrigues HG, Vinolo MA, Sato FT, Magdalon J, Kuhl CM, Yamagata AS, et al. Oral administration of linoleic acid induces new vessel formation and improves skin wound healing in diabetic rats. PLoS One 2016;11(10):e0165115.

42. Declair V. The usefulness of topical application of essential fatty acids (EFA) to prevent pressure ulcers. Ostomy Wound Manage 1997;43(5):48-52.

43. Politis MJ, Dmytrowich A. Promotion of second intention wound healing by emu oil lotion: comparative results with furasin, polysporin, and cortisone. Plast Reconstr Surg 1998;102(7):2404-7.

44. Farahpour MR, Vahid M, Oryan A. Effectiveness of topical application of ostrich oil on the healing of Staphylococcus aureusand Pseudomonas aeruginosa-infected wounds. Connect Tissue Res 2018;59(3):212-22.

45. Jackson JE, Kopecki Z, Cowin AJ. Nanotechnological advances in cutaneous medicine. J Nanomaterials 2013;2013.

46. Perez-Recalde M, Ruiz Arias IE, Hermida EB. Could essential oils enhance biopolymers performance for wound healing? A systematic review. Phytomedicine 2018;38:57-65.

47. Liakos I, Rizzello L, Scurr DJ, Pompa PP, Bayer IS, Athanassiou A. All-natural composite wound dressing films of essential oils encapsulated in sodium alginate with antimicrobial properties. Int $\mathrm{J}$ Pharm 2014;463(2):137-45.

48. Low WL, Kenward MAK, Amin M, Martin C. Ionically crosslinked chitosan hydrogels for the controlled release of antimicrobial essential oils and metal ions for wound management applications. Medicines (Basel) 2016;3(1).

49. Flores FC, De Lima JA, Da Silva CR, Benvegnu D, Ferreira J, Burger $\mathrm{ME}$, et al. Hydrogels containing nanocapsules and nanoemulsions of tea tree oil provide antiedematogenic effect and improved skin wound healing. J Nanosci Nanotechnol 2015;15(1):800-9.

50. Silva JR, Burger B, Kuhl CMC, Candreva T, Dos Anjos MBP, Rodrigues HG. Wound healing and omega- 6 fatty acids: from inflammation to repair. Mediators Inflamm 2018;2018:2503950.

51. Riley TV, Carson CF. Emu oil: its anti-inflammatory and anti-viral potential. Western Australia: University of Western Australia; 1999. Contract No.: 99/132

52. Buthelezi S, Southway C, Govinden U, Bodenstein J, du Toit K. An investigation of the antimicrobial and anti-inflammatory activities of crocodile oil. J Ethnopharmacol 2012;143(1):325-30.

\section{CORRIGENDUM}

Title: Study protocol: a pilot clinical trial of topical glyceryl trinitrate for chronic venous leg ulcer healing

Authors: Miles SJ, Lord R, Williams D \& Fulbrook P

Volume 27 , issue 3 , page 131

DOI https://doi.org/10.33235/wpr.27.3.131-134

Correction: Methods section in Abstract.

The concentration of GTN ointment used in the study is indicated as $2 \%$ and should be $0.2 \%$.

This error does not appear elsewhere in the publication (e.g. study design under methods section where the GTN concentration is correctly given as $0.2 \%$ ).

The authors apologise for any confusion caused. 